\title{
Pedagogia da variação linguística e estudo de gêneros numa sociedade multidialetal
}

\author{
Lúcia Cyranka \\ Terezinha Barroso \\ Universidade Federal de Juiz de Fora
}

\section{Resumo}

Este artigo apresenta os resultados de investigação em escola pública de Juiz de Fora (Minas Gerais) que atende a adolescentes da classe popular, com descompasso entre idade/ano escolar. Estudos sociolinguísticos (Soares, 1995; Rojo, 2009; Faraco, 2008; Bortoni-Ricardo, 2009) e do interacionismo sociodiscursivo (Dolz, Pasquier \& Bronckart, 1993; Dolz \& Schneuwly, 2004) ofereceram subsídios para a pesquisa, que tem indicado serem os fatores importantes na determinação do fracasso escolar: (i) ausência de reflexão sistemática sobre variação linguística, (ii) correspondência inadequada entre variação linguística e registro de língua e (iii) subutilização dos gêneros textuais como ferramentas pedagógicas produtivas.

Palavras-chave: Sociolinguística educacional. Interacionismo sociodiscursivo. Variação linguística. Gêneros textuais. 


\section{Pedagogy of linguistic variation and the study of genders in a multi-dialectical society}

We present the results of an investigation in a public school in the town of Juiz de Fora (MG), in which working class adolescents, who are not the usual age corresponding to their grade, study. Sociolinguistic studies (Soares, 1995; Rojo, 2009; Faraco, 2008; Bortoni-Ricardo, 2009) and studies of socio-discursive interactionism (Dolz, Pasquier \& Bronckart, 1993; Dolz \& Schneuwly, 2004), which have indicated important factors in determining failure in school, subsidized the research. Such factors include: (i) the absence of systematic reflection on linguistic variation, (ii) inadequate correspondence between linguistic variation and the recording of the language, and (iii) underutilization of text genre as productive educational tools.

Keywords: Sociolinguistics. Socio-discursive interactionism. Linguistic variation. Textual genre.

\section{La pedagogía de la variación lingüística y el estúdio de géneros en una sociedade multidialectal}

Se presentan resultados de investigación en escuela pública de Juiz de Fora (MG), que atiende a adolescentes clase popular con desajuste entre edad/año escolar. Estudios sociolingüísticos (Soares, 1995; Rojo, 2009; Faraco, 2008; Bortoni-Ricardo, 2009) e interaccionismo sociodiscursivo (Dolz, Bronckart y Pasquier, 1993; Dolsz y Schneuwly, 2004) ofrecieron insumos teóricos para este estudio, que há demostrado los factores determinantes en el fracaso escolar: (i) ausencia de reflexión sistemática sobre variación linguística; (ii) correspondencia inadecuada entre variación linguística y registro de la lengua; (iii) infrautilización de los géneros textuales como herramientas de enseñanza productivas.

Palabras-clave: Sociolingüística educacional. Interaccionismo sociodiscursivo. Variación linguística. Géneros textuales. 


\section{Introdução}

A tríade alfabetização/letramento, classes populares e sucesso escolar tem ocupado posição de destaque nos embates acadêmicos, com repercussão em políticas educacionais de avaliação de desempenho escolar, tais como Sistema de Avaliação da Educação Básica (Saeb), Prova Brasil e o Programa de Avaliação da Alfabetização (Proalfa). Nas últimas décadas do século XX, o ensino de língua portuguesa experimentou momentos propícios de debate e renovação, que levaram a uma reavaliação profunda do conceito de língua e linguagem, amparado, principalmente, pelos estudos da pragmática, da sociolinguística, da linguística textual e os de base enunciativo-discursiva. Maior ênfase foi dada às pesquisas aplicadas na área do ensino. Um conjunto rico de orientações curriculares, desde então, tem sido produzido nas diferentes instâncias governamentais, estadual e municipal, e guiado a elaboração de materiais didáticos disponibilizados ao professor, principalmente pelo Programa Nacional do Livro Didático (PNLD). Um dos grandes valores desses documentos foi o de formalizar e dar legitimidade a uma visão de ensino de língua que a concebesse como construto situado e partilhado sócio-historicamente.

Esses estudos e pesquisas apoiam-se em uma concepção de linguagem, de base sociointeracionista, inspirada, principalmente, em Bakhtin ([1954]2000) e Vygotsky ([1936]1996) que, a partir da década de 1990, recebeu contribuições relevantes do interacionismo sociodiscursivo, advindas do grupo de Genebra (Bronckart, 1999; Dolz, Pasquier \& Bronckart, 1993; Dolz \& Scheneuwly, 2004 e outros). Aplicado à transposição didática para o estudo dos gêneros textuais como objeto de ensino nas práticas de sala de aula, o interacionismo sociodiscursivo possibilita uma abordagem situada da linguagem, que a concebe como ação semiotizada, resultante de parâmetros contextuais, psicossociais e linguísticos. Reforçam esse olhar sobre a linguagem os estudos sociolinguísicos (Labov,1995,2002, 2008; Bortoni-Ricardo, $2004,2005,2011$; Faraco, 2008) que veem a linguagem como expressão da cultura, a qual, portanto, não pode ser tratada a não ser sob o viés da variação e da mudança. 0 diálogo entre essas duas vertentes complementares permite uma associação bem sucedida entre o conceito de gênero textual, tomado na sua constituição heterogênea, de relativa instabilidade, e o conceito de heterogeneidade linguística, base para os estudos sobre variação linguística e sua aplicação didático-metodológica no ensino de língua.

No presente trabalho, pretendemos refletir sobre os procedimentos didáticos necessários para se implementar, na escola básica, uma pedagogia da variação linguística. Esta deve contemplar a efetiva ampliação de competência de uso da língua em suas modalidades oral e escrita, tomando-se os gêneros textuais como espaço de realização discursiva da linguagem, nos diferentes estilos requeridos pelas situações reais de uso.

Para isso, tomamos como foco uma pesquisa-ação iniciada em escola pública 
do município de Juiz de Fora (MG). Ainda em fase de implementação, a pesquisa tem nos revelado, no entanto, ser não apenas possível construir essa perspectiva didático-pedagógica, mas também ser imprescindível instrumentalizar os professores com novas teorias trazidas pela linguística da enunciação, que, infelizmente, permanecem, em grande parte, ainda ausentes dos cursos atuais de formação de professores e das práticas das gerações que os antecederam.

Na primeira parte do trabalho, apresentamos um esboço das orientações que têm fundamentado nossa investigação, do ponto de vista da compreensão da teoria dos gêneros textuais e da sociolinguística educacional. A seguir, apresentamos uma contextualização da pesquisa, seguida das constatações feitas nas turmas eleitas como foco, apontando para a deficiência do trabalho escolar nessas duas dimensões.

\section{Gêneros textuais e ensino: as contribuições do interacionismo so- ciodiscursivo}

Para Bronckart, as condutas humanas são mediadas e organizadas pela linguagem, e é a partir dela, concebida como ferramenta semiótica, que o homem se apropria do mundo, age e interage com o outro. 0 autor esclarece:

A espécie humana caracteriza-se (...) pela extrema diversidade e pela complexidade de suas formas de organização e de suas formas de atividade. Essa evolução espetacular está indissoluvelmente relacionada à emergência de um modo de comunicação particular, a linguagem, e essa emergência confere às organizações e atividades humanas uma dimensão particular, que justifica que sejam chamadas sociais (...). (Bronckart, 1999, p.31, grifo nossol

A linguagem, então, é constitutiva do psicológico humano e, nessa perspectiva, o interacionismo sociodiscursivo a concebe como forma de ação, como mediadora e organizadora das interações do homem no mundo. Assim tomada, a linguagem se apresenta como um construto psicológico, cognitivo e social. Componente do agir humano, na dimensão a que Habermas (1987) denominou de agir comunicativo, a linguagem deve ser analisada a partir da relação que se instaura, no momento de seu uso, com os parâmetros do contexto social, a que Bronckart (1999, p.91) denomina de situação de ação de linguagem. Isso significa que a língua não é fruto de construção individual, descontextualizada, mas é prática social. Sua materialização se dá por meio de uma unidade comunicativa - o texto empírico - que se constrói por sujeitos reais, que usam a língua para promover diferentes ações de linguagem: convencer, contar caso, dar opinião, dar conselho, passar receitas, fazer declaração de amor, etc. Essa forma de conceber a linguagem dada pelo interacionismo sociodiscursivo 
situa o sujeito, o contexto e o discurso como componentes indissociáveis do processo de semiotização do pensamento, traços que garantem plasticidade e dinamicidade à língua.

Se a posição aqui defendida é a de que a linguagem é forma de ação e que se constrói por meio do discurso situado e (com)partilhado, temos que reconhecer dois aspectos relevantes dessa construção: (1) as aç̃ões de linguagem expressam intenções comunicativas de sujeitos sociais a partir de experiências inter e intrassubjetivas; (2) as formas de organização do discurso estão vinculadas às esferas sociais de comunicação, nas quais esses discursos circulam. Daí decorre a noção de gênero textual ou do discurso, como posto por Bakhtin (1953/2000).

Segundo o autor, todo uso que fazemos da língua se dá por meio de um texto - oral ou escrito -, realização empírica de um gênero de texto, e esses usos são institucionalizados, legitimados por instâncias da atividade humana, socialmente organizadas. Por sua vez, essas instâncias de atividade humana - as esferas sociais de comunicação - elegem seus próprios gêneros, o que permite a fácil comunicação/ interação entre os membros de uma comunidade discursiva. (Swales, 1990).

Segundo Bakhtin, os gêneros do discurso:

[...] nos são dados quase como nos é dada a língua materna, que dominamos com facilidade, antes mesmo que lhe estudemos a gramática [...] Aprender a falar é aprender a estruturar enunciados [...] Os gêneros do discurso organizam nossa fala da mesma maneira que a organizam as formas gramaticais. [...] Se não existissem os gêneros do discurso e se não os dominássemos, se tivéssemos de construir cada um de nossos enunciados, a comunicação verbal seria quase impossível. (Bakhtin, 2000, p. 301-302)

Tomando o funcionamento da língua em seus aspectos sociais, cognitivos, históricos e discursivos, essa perspectiva epistemológica da linguagem coloca-se em contraposição à visão objetivista, que a concebe apenas como forma. Assumindo uma posição contrária às abordagens tradicionais que priorizam o ensino sobre a língua, com foco restrito no ensino da metalinguagem, o interacionismo sociodiscursivo volta-se para o ensino da língua a partir de suas atualizações nas diferentes esferas comunicativas e promove uma revisão sobre as práticas de linguagem, elegendo como objeto de ensino o texto empírico, atualizado em diferentes gêneros textuais orais e escritos.

Não há como nos comunicarmos, a não ser por meio dos gêneros de texto orais ou escritos. Os gêneros textuais funcionam como modelos de referência para o usuário da língua. Seu processamento pelo sujeito se dá automática e intuitivamente no intertexto, em situações imediatas de uso (gêneros primários), ou através de metareflexão, em situação de aprendizado formal, por meio de gêneros mais complexos (gêneros secundários).

Sob essa perspectiva, a transposição didática do interacionismo sociodiscursivo para uma abordagem didática dos gêneros textuais, tomados como objeto de 
ensino, contempla três aspectos principais: (1) o reconhecimento da participação, no momento da produção textual (oral ou escrita), do conjunto de representações sociais que constituem as condições de produção do discurso: os mundos físico e sociossubjetivo, que servem ao sujeito como base de orientação para a decisão estratégica por um dado gênero textual e por sua forma de codificação linguística e discursiva; (2) uma (meta)reflexão que promova o reconhecimento do papel relevante dessa codificação para uma escolha bem sucedida do gênero, harmonizada com a ação de linguagem pretendida: a arquitetura interna do texto - a infraestrutura geral do texto, os mecanismos de textualização e os mecanismos enunciativos. (Bronckart, 1999)

Nessa direção, as práticas escolares de ensino e aprendizagem, pautadas no desenvolvimento da competência para o uso da língua em gêneros, passam a ter um caráter social e funcional e a se guiarem por objetivos mais claramente definidos: aprender a escrever para reclamar direitos (carta de reclamação), aprender a ler para se informar sobre onde assistir a um filme (agenda cultural), aprender a ler para admirar uma obra (romance), aprender a "falar" para se apresentar a um emprego (entrevista), conhecer e dominar os recursos linguístico-discursivos para provocar e compreender efeitos de sentido.

Ao destacarmos o caráter social e partilhado da linguagem e sua produção situada, sob o viés do interacionismo sociodiscursivo, abrimos espaço para a heterogeneidade do discurso, para a intertextualidade discursiva, para as vozes que o constituem, para a diversidade cultural.

Como visto, as escolhas linguísticas e discursivas, a infraestrutura geral de um determinado texto são semioses das representações construídas pelos sujeitos da situação de produção, base de orientação para a produção textual. É exatamente apoiada nessa base de orientação para a produção textual que a escolha por uma variante linguística, e não outra, vai ser legitimada, à medida que melhor se adeque ao conteúdo temático, ao estilo do enunciador e às suas intenções comunicativas. É nesse ponto que a pedagogia da variação linguística, sob o aporte teórico advindo da sociolinguística, entra para fundamentar e enriquecer o planejamento de uma transposição didática que conceba a língua na sua forma e função social. É o que discutiremos a seguir.

\section{Pedagogia da variação linguística: as contribuições da sociolinguística}

Os estudos da sociolinguística fazem-nos avaliar a ineficácia das teorias voltadas para as deficiências culturais e linguísticas como aportes para a explicação do fracasso escolar, não reconhecendo o valor determinante das relações entre linguagem, escola e sociedade, o que gera, por conseguinte, uma postura prescritiva e valorativa frente a variantes linguísticas que se distanciem da norma culta. A 
mesma postura discriminatória guia os procedimentos didático-pedagógicos de ensino de língua nas escolas públicas, aprofundando, ainda mais, a distância entre a variedade linguística utilizada pelo aluno e a que a escola the apresenta como, na melhor das hipóteses, a mais prestigiada.

Tal situação, portanto, precisa ser modificada por uma ação efetiva, por parte dos agentes escolares, orientados pelos avanços teóricos que, principalmente, o século $X X$, conforme afirmamos acima, produziu em relação às questões de linguagem e ensino de línguas. De fato, a construção de teorias nessa área de conhecimento precisa ser acompanhada de uma efetiva repercussão na escola, agência responsável pela formação do homem capaz de transformar a sociedade, tornando-a cada vez melhor.

Do ponto de vista da sociolinguística, há um trabalho imenso a ser empreendido na construção de um saber voltado para a desconstrução de crenças que, embora nascidas em épocas muito distanciadas das atuais, têm sido cultivadas e preservadas em prejuízo de muitas gerações que, por isso mesmo, foram privadas do acesso aos bens culturais. Referimo-nos ao domínio da linguagem nas suas variedades prestigiadas, expressão de poder e de competência. Ainda que, do ponto de vista científico, nada de efetivamente linguístico se possa reconhecer de real mais valia na linguagem, as relações intrínsecas entre língua, cultura e sociedade resultam nas atitudes positivas ou negativas dos falantes frente aos dialetos sociais.

Essa é, como se sabe, uma questão inerente a todas as línguas. No entanto, do ponto de vista da educação escolar e do trabalho com o desenvolvimento de competências de uso da língua materna, ela se tornou tema importantíssimo. Longe estamos ainda de conseguir concretizar ações efetivas na superação das dificuldades nessa área. Nos Estados Unidos, por exemplo, a questão do tratamento escolar inadequado dado às crianças negras urbanas falantes da variedade do inglês vernacular afro-americano (AAVE) tem sido alvo de reflexões de muitos sociolinguistas (Labov, 1995; Wolfram, 1999; Wheeler S. Rebeca, 2004, 2005 e 2008, etc). Igualmente, no Brasil, vários deles estão empenhados no processo de desconstrução do mito da variedade padrão como modelo a ser adotado (Faraco, 2008). Isso porque esse conceito implica contradições inerentes à própria compreensão do que seja a língua: fenômeno heterogêneo, mutante, híbrido, dotado de organização. Para os defensores do ideal do modelo padrão, desviar-se do que preceitua a gramática normativa é desorganizar a língua, comprometendo-lhe a beleza e a unidade. A variação, em consequência, é considerada erro lamentável. Emblemático desse grave equívoco e das dimensões a que tem chegado foi a que ficou conhecida como "questão do livro didático", acontecida no Brasil em 2011, quando alguns segmentos da sociedade se indignaram com o tratamento dado pelas autoras ao fenômeno da variação no livro didático "Viver e aprender: por uma vida melhor" 1 . Nele, reconheceram como existentes no português brasileiro e, portanto,

1. 0 livro se destina à EJA - Educação de Jovens e Adultos. A edição é de responsabilidade da Ação Educativa - Maio de 2011. 
possíveis em nossa língua, construções como "Os livro" e "Nós pega o peixe".

Melhor é que se parta do conceito de variedades cultas, que reconhece seus falantes como os que têm amplo acesso à cultura letrada e aos bens culturais ligados ao acesso à língua escrita. Tudo indica, no entanto, que essas variedades chamadas cultas não coincidem com a variedade padrão. Foi essa a conclusão a que chegaram as pesquisas realizadas pelo projeto NURC ${ }^{2}$. Uma das surpreendentes conclusões desse projeto está descrita por Preti, ao caracterizar o falante culto (nível universitário). 0 autor assim o descreve:

[...] um falante de um dialeto social dividido entre as influências de uma linguagem mais tensa, marcada pela preocupação com as regras de gramática tradicional, e uma linguagem popular, espontânea, distensa. Portanto, essa hipotética linguagem urbana comum comportaria oposições como a presença de uma sintaxe dentro das regras tradicionais da gramática ao lado de discordâncias, regências verbais de tendência uniformizadora, colocações dos componentes da frase justificadas pelos elementos prosódicos, como no caso dos pronomes pessoais; abrangeria a precisão de um vocabulário técnico, ao lado da abertura de significado de vocábulos gírios; utilizaria vocábulos raros, de significação precisa, específica, concomitantemente com vocábulos populares de uso constante e de significado aberto. (Preti,1997, p. 17)

As orientações dos PCNs convergem com essas conclusões quando advertem:

Não existem, portanto, variedades fixas: em um mesmo espaço social convivem mescladas diferentes variedades linguísticas, geralmente associadas a diferentes valores sociais. Mais ainda, em uma sociedade como a brasileira, marcada por intensa movimentação de pessoas e intercâmbio cultural constante, o que se identifica é um intenso fenômeno de mescla linguística, isto é, em um mesmo espaço social convivem mescladas diferentes variedades linguísticas, geralmente associadas a diferentes valores sociais. (PCNS, 1998, p. 29)

As variedades linguísticas, ou diferenças dialetais, são o resultado dessa complexa e diferenciada constituição e vão sendo marcadas e reconhecidas a partir de determinado critério de valorização/desvalorização dos grupos sociais que as utilizam. Nas sociedades em que as diferenças econômicas estão na base da constituição desses grupos, como é o caso do Brasil, o valor positivo atribuído às variedades linguísticas é diretamente proporcional a essas diferenças. (BortoniRicardo, 2005, p. 131)

A variação e a mudança são, portanto, dois fenômenos que devem subsidiar o trabalho com a linguagem na escola. As atividades didáticas que, pelo menos, não incluírem esse pressuposto são, no mínimo, ingênuas e improdutivas quanto ao

2. PROJETO NURC (Norma urbana culta) tem como objetivo pesquisar as normas cultas de Recife, Salvador, Rio de Janeiro, São Paulo e Porto Alegre, na modalidade falada, e investigar o registro coloquial e o da norma refletida nesse mesmo espaço social. (V. Castilho, 2002) 
desenvolvimento de competências de uso da língua. Faraco (2008, p. 182) propõe que se construa uma pedagogia da variação linguística:

Isso posto, cabe reiterar que nosso grande desafio, neste início de século e milênio, é reunir esforços para construir uma pedagogia da variação linguística que não escamoteie a realidade linguística do país (reconheça-o como multilíngue e dê destaque crítico à variação social do português): não dê um tratamento anedótico ou estereotipado aos fenômenos da variação; localize adequadamente os fatos da norma culta/comum/standard no quadro amplo da variação e no contexto das práticas sociais que a pressupõem; abandone criticamente 0 cultivo da norma padrão; estimule a percepção do potencial estilístico e retórico dos fenômenos da variação.

Acreditando ser esse, de fato, o caminho a trilhar, investigações vêm sendo realizadas no grupo de pesquisa FALE (Formação de Professores, Alfabetização, Linguagem e Ensinol da Faculdade de Educação da Universidade Federal de Juiz de Fora (UFJF) e no programa de pós-graduação dessa mesma unidade de ensino, procurando subsídios para a implementação dessa proposta.

No presente artigo, apresentamos algumas constatações feitas na pesquisa que vem sendo realizada sob o patrocínio da UFJF, intitulada Implementação da pedagogia da variação linguística e ensino de gêneros na escola. (BIC/UFJF 2013/2014l

A metodologia adotada tem sido a pesquisa-ação, durante a qual, em linhas gerais, buscamos atingir os seguintes objetivos: i) constituir, com os professores da disciplina língua portuguesa do ensino fundamental, um modo de pensar sociolinguístico que oriente suas atividades didáticas; ii) pesquisar estratégias, a partir de proposições teórico-práticas, permitindo que os alunos utilizem seu vernáculo, orientando-os, ao mesmo tempo, para que ampliem sua competência linguística de modo a aprenderem as variedades prestigiadas da língua portuguesa, utilizadas na construção do conhecimento científico na escola; iii) implementar junto aos alunos, com a colaboração de seus professores, os diversos usos da língua, de acordo com cada contexto sociocomunicativo, aí incluído, portanto, o trabalho com os gêneros textuais, de modo a levá-los a refletir sobre a legitimidade das variedades linguísticas e perceber a possibilidade de se tornarem bidialetais; iv) respeitar 0 vernáculo dos alunos, para a construção de suas atitudes e crenças positivas sobre ele, estimulando-os, ao mesmo tempo, a ampliarem sua competência linguística em direção ao domínio das variedades cultas, ensinadas pela escola.

Essas ações têm sido implementadas no segundo segmento do ensino fundamental de uma escola pública do município de Juiz de Fora (MG). Os sujeitos da pesquisa são falantes de dialetos sociais próprios de comunidades pobres, distanciadas, portanto, das variedades conhecidas como cultas. Trabalhos anteriores realizados em contextos escolares semelhantes têm mostrado que esses alunos são capazes não apenas de compreender, sem dificuldade, o fenômeno da variação 
linguística, mas, o que é mais importante, percebem-se sob a orientação da escola para irem, pouco a pouco, ampliando seus recursos linguísticos tanto nos aspectos fonético/fonológicos, quanto morfossintáticos, lexicais e até mesmo discursivopragmáticos. Esses resultados têm sido divulgados em publicações científicas e em congressos ${ }^{3}$.

As constatações acima aludidas têm como foco a necessidade da formação do professor para o desenvolvimento de uma pedagogia da variação linguística associada ao trabalho com os gêneros textuais.

É no curso atualizado dessas discussões que nos posicionamos agora, buscando responder as seguintes questões que traduzem os objetivos específicos de nossa pesquisa:

Os professores de língua portuguesa da escola têm se apossado dos estudos sobre gênero textual, que o tomam como objeto de ensino para o desenvolvimento da competência linguística e discursiva?

Os professores de língua portuguesa fazem uso de uma pedagogia da variação como fundamento de suas práticas escolares?

Como se dá a transposição didática dos estudos de gêneros textuais e da variação linguística?

\section{0 contexto da pesquisa e seus sujeitos}

As pesquisas A pedagogia da variação linguística na escola (BIC/UFJF/20122013) e Implementação da pedagogia da variação linguística e ensino de gêneros na escola (BIC/UFJF-2013/2014) têm a participação de dois professores pesquisadores da UFJF/FACED PPGE/PPGP e o acompanhamento de três bolsistas. As atividades vêm sendo desenvolvidas no grupo de pesquisa FALE (Formação de Professores, Alfabetização, Linguagem e Ensino). A instituição foco do estudo é uma escola municipal do município de Juiz de Fora, MG, que, segundo informações da Secretaria Municipal de Educação ${ }^{4}$, apresenta características próprias quanto à clientela e organização curricular, atende a alunos adolescentes de classe baixa, provenientes de diferentes bairros da cidade, com defasagem idade/ano escolar por retenção no sexto ano do ensino fundamental de, em média, três anos na instituição de origem, ou mesmo por evasão escolar. Muitos desses alunos apresentam histórico de violência e desajuste psicossocial e ingressam na escola com o objetivo de ajustarem seu tempo escolar, numa convivência diferenciada com a nova realidade, logrando, assim, melhor desempenho na aprendizagem.

3. Cf. CYRANKA, Lucia F. Mendonça. Dos dialetos sociais às variedades cultas: a Sociolinguística na escola. Curitiba: Appris, 2011. Nessa obra, estão reunidos relatos de trabalhos realizados em escolas, na construção de uma pedagogia da variação linguística.

4. Informações disponíveis em: http://www.pjf.mg.gov.br/noticias/view.php?modo=link2\&idnoticia2=32572. Acesso em: 21 jan. 2012 
Para a concretização de sua proposta pedagógica, a escola conta com uma equipe de professores da rede que, diferentemente dos procedimentos regulares de alocação de docentes, não foi designada, mas fez opção por atuar na instituição e aceitar o desafio. Para o desenvolvimento dos conteúdos curriculares, arranjados ao longo de dois anos ${ }^{5}$, a escola busca enfrentar o desafio da diversidade, propondo formas e espaços alternativos de aprendizagem, utilizando-se, além da sala de aula, de laboratórios de novas tecnologias (com acesso à internet) e oficinas de matemática, ciências, contação de história, cinema e rádio.

A busca por formas alternativas e bem fundamentadas teórica e metodologicamente para o ensino de língua portuguesa tem sido um grande motivador da escola. Daí o convite feito pelos professores de português ao grupo de pesquisa FALE da FACED/UFJF.

A pesquisa de caráter qualitativo, com base na prática reflexiva coletiva e na pesquisa-ação (Kemmis; Taggart, 1988), tem como objetivo um contato direto com os professores e suas aulas. Tomando como critério a abordagem qualitativa da pesquisa, os seguintes instrumentos de coleta de dados têm sido adotados:

- análise documental, com identificação das orientações curriculares que norteiam o ensino de língua portuguesa na escola, em comparação com aquelas apresentadas pela proposta curricular de língua portuguesa da rede municipal;

- protocolo das reuniões quinzenais com professores;

- anotações de campo, produzidas por alunos bolsistas dos cursos de letras e Pedagogia da UFJF, com registros de práticas de linguagem.

Nas reuniões com o grupo de professores, tem-se buscado construir um diálogo que permita um olhar crítico sobre a prática docente e que promova mudança. Três temáticas têm guiado a dinâmica desses encontros:

- as orientações curriculares para o ensino de língua portuguesa, praticado na escola, considerando-se, na discussão, a especificidade do perfil de aluno já descrito neste artigo e a apropriação das orientações da Proposta Curricular de língua portuguesa da rede municipal, em fase de implantação;

- o grau de implicação dos professores numa pedagogia da variação linguística que considere os gêneros textuais como espaço legítimo de realização da linguagem oral ou escrita, tomado pelo viés interacionista e sociodiscursivo;

- o planejamento coletivo de ações didático-pedagógicas para o desenvolvimento da competência linguística dos alunos, envolvendo, na medida do possível, práticas interdisciplinares.

5. Os alunos que se matriculam na escola devem estar cursando $06^{\circ}$ ano e a meta é que completem os estudos do segundo segmento do ensino fundamental em dois anos. 


\section{Práticas observadas - o que se faz, o que há por fazer}

Retomamos, nesta seção, as perguntas postas como guia de nossa observação sobre as práticas docentes de professores de língua portuguesa na escola em estudo, voltadas ao desenvolvimento da competência comunicativa para o uso da língua em gêneros textuais:

Os professores de língua portuguesa da escola têm se apossado dos estudos sobre gênero textual, que o tomam como objeto de ensino para o desenvolvimento da competência linguística e discursiva?

Como se dá a transposição didática dos estudos de gêneros textuais para a aula de língua portuguesa?

As atividades didáticas têm se inspirado numa reflexão sociolinguística de modo a levar os alunos a construírem sua identidade por meio do uso de seu dialeto, ao mesmo tempo em que se percebem orientados pela escola no processo de ampliação de sua competência linguística?

\section{Gêneros textuais e ensino}

Os dados preliminares nos permitem tecer as observações que se seguem. Tomados como dados singulares nesse primeiro estágio de nossa investigação, servirão para aprofundamentos futuros e generalizações mais seguras.

Destacamos abaixo fragmentos de relatos feitos pelos bolsistas em seus diários de campo sobre as práticas observadas ${ }^{6}$ de um dos professores. A análise das práticas de transposição didática assenta-se sobre (1) a concepção de gênero adotada pelo professor e (2) o rebatimento dessa concepção na transposição didática, manifestada nas atividades de linguagem propostas em aula.

Os diários de campo revelam-nos a percepção pouco aprofundada do professor sobre o conceito em estudo, ou seja, o gênero de texto não é reconhecido pela atividade social que o constitui, pela ação de linguagem que promove, mas por suas propriedades essencialmente formais, a partir de atividades didáticas de classificação e reconhecimento do gênero.

Transcrevemos, a seguir, trechos das anotações de campo feitas pelas bolsistas de iniciação científica, que participam do projeto e que ilustram tratamento inadequado no tratamento dos gêneros textuais.

No primeiro exemplo, o enfoque enunciativo e discursivo é colocado em segundo plano, ou nem sempre considerado, para dar lugar a práticas de identificação do gênero pela mera nomeação, como ilustrado no registro a seguir ${ }^{7}$ :

\footnotetext{
6. Pelo caráter preliminar da pesquisa, para este artigo, não consideramos os registros das reuniões reflexivas com os professores, dados relevantes que, posteriormente, serão analisados e cruzados com a avaliação das práticas docentes e o material didático utilizado.

7. Agradecemos à bolsista Viviane Alves de Matos, aluna do Curso de Letras da UFJF, pelas anotações de campo utilizadas neste artigo.
} 


\section{$29 / 1 / 2013$}

A professora falou com os alunos que eles continuariam trabalhando o gênero textual já visto e entregou-lhes duas folhas, a primeira com o título Anúncio. Ela perguntou aos alunos: "- Qual gênero textual nós vamos trabalhar hoje?". Diante disso a Melissa perguntou: "- 0 quê? Gênero textual?". Logo em seguida, a professora indagou: "-Vamos trabalhar a continuidade de qual gênero?". Sérgio respondeu que era o "vende-se" e a Melissa que era o "anúncio".

Outras vezes, a atividade de nomeação chega ao desafio da adivinhação. A partir de uma pista pouco significativa, propõe-se aos alunos a tarefa de adivinharem o gênero de texto incluído no planejamento do dia:

08/10/2012

A professora disse aos alunos que faria, no quadro, um esboço de um gênero textual, para que eles descobrissem qual era ele. 0 esboço que ela fez constava de um quadro escrito "Contato: 3232-9013". Os alunos Vagner e Sérgio falaram que aquele esboço poderia ser um título de eleitor, um contrato de aluguel, um CPF, um comprovante de residência, uma carteira de identidade, um currículo ou um contrato. Diante disso, a professora falou que era um anúncio e o Vagner mencionou que poderia ser um anúncio de troca, venda ou aluga-se.(...)

Outra prática presente nas aulas de leitura e escrita é aquela que expressa a preocupação do professor com o uso da metalinguagem, ranço de uma visão formalista, que se apoia na tese de que a competência comunicativa do sujeito advém de sua capacidade de nomear fenômenos da língua e de dominar conceitos e regras gramaticais. Mais uma vez, aqui vale a capacidade de nomear e reconhecer a nomenclatura própria do objeto em estudo, como equivalente à capacidade de produzir significados, faltando à prática docente uma condução para a reflexão sobre os usos dos gêneros e suas formas linguísticas de codificação. No relato a seguir, nota-se também o equívoco do professor quanto ao entendimento do conceito de suporte e de como se dá sua manifestação nas esferas sociais:

\section{9/10/2012}

Posteriormente, a R mostrou um jornal e perguntou: "- Que gênero textual vocês acham que vamos trabalhar hoje?". Sérgio respondeu equivocadamente: "- Estado de Minas". A professora voltou a indagar: "- Não, Estado de Minas é o nome do jornal. Quero saber o gênero, o tipo de texto". Como nenhum aluno respondeu, a professora falou que era a notícia, a reportagem.

Achei estranho o modo como ela formulou essa pergunta, já que o jornal é um suporte que comporta muitos gêneros, não só a notícia.(...)

E a professora prossegue: 
$19 / 11 / 2012$

“- Quantos tipos de suporte eu trouxe?" - escrevendo no quadro os nomes dos jornais citados pelos alunos e complementando: "- São quatro tipos, são suportes diferentes, nomes de jornais diferentes".

Como podemos perceber, a pergunta da professora não foi bem formulada, pois havia apenas um suporte (o jornal) e diferentes tipos de jornais. Com essa pergunta, os alunos podem ter ficado confusos, tendo a possibilidade de pensarem que suporte corresponde ao nome do jornal. (...)

No que respeita às atividades de escrita, o quadro descrito adquire proporções também preocupantes: atividades de reescrita descontextualizadas, exercício de vocabulário compõem grande espaço das aulas e pouca reflexão linguística, como descrito abaixo:

$22 / 10 / 2012$

A professora passou uma atividade para que os alunos reescrevessem anúncios, escrevendo as abreviaturas (dos classificados) por extenso.

Em seguida, a professora passou no quadro os seguintes dados para os alunos copiarem:

“Gênero textual: notícia/ reportagem

Suporte: jornal (veículo de comunicação) (...)"

Ou:

29/10/2012

Posteriormente, Sérgio continuou lendo o material dado pela professora; esta ia corrigindo os pequenos "erros" na leitura do aluno, além de fazer perguntas a respeito do significado de alguns termos e palavras presentes nos anúncios, tais como: "- 0 que é localização privilegiada?"; “- Por que não tem o finalzinho do número dos telefones?" (referindo-se aos números finais dos telefones dos anúncios, como por exemplo: 5679 XXXX); “- 0 que é madeira maciça? E o que são seminovas?"

Para finalizar, vale novamente ressaltar o caráter incipiente dessas observações, tomadas como indícios para a necessidade de aprofundamento de uma pesquisaação de base reflexiva. Como já antecipado, vários procedimentos didáticometodológicos fundamentais a uma prática que elege o gênero textual como objeto de ensino são omitidos nas aulas desses professores. Ainda resiste a visão formalista, que deixa de lado aspectos constitutivos do gênero, tais como o contexto de situação nos quais se atualizam como ações de linguagem; a articulação entre a representação do gênero e a semiose linguística disponível para sua codificação, uma prática de reflexão linguística que leve em conta, por exemplo, as variações 
linguísticas e que desenvolva a autonomia do aluno como usuário da língua.

Os dados trazidos para reflexão neste estágio são ferramentas fundamentais para entendermos o processo de compreensão do professor sobre os estudos de gêneros e sua apropriação para a transposição didática, assim como para o planejamento de reuniões reflexivas com os professores.

\section{A pedagogia da variação linguística na escola: o que há por fazer}

Os alunos sujeitos da pesquisa, conforme dito acima, moram, em sua totalidade, nos bairros periféricos da cidade, onde predomina a fala rurbana (Bortoni-Ricardo, 2004), caracterizada pela presença dos chamados traços descontínuos, explicados por essa autora como aqueles que "[...] têm uma distribuição descontínua, porque seu uso é 'descontinuado' nas áreas urbanas" (Bortoni-Ricardo, 2004, p. 53). Esses traços são estigmatizados, recebendo uma avaliação negativa nos centros urbanos. Por outro lado, pertencendo todos eles a redes sociais ${ }^{8}$ diversificadas, têm contato com falantes cuja variedade linguística predominante é a chamada linguagem urbana comum, a que já nos referimos acima (Preti, 1995), o que os faz incorporar traços linguísticos desse outro segmento social, por força das pressões exercidas pelo contato nos grupos que frequentam, além da mídia e da ação da escola.

0 período de contato que tivemos com os alunos dessa escola nos possibilitou identificar neles, por um lado, uma preocupante descrença em sua própria competência, acrescida pela autopercepção de falantes de uma variedade linguística desprestigiada; por outro lado, e talvez como consequência disso, são agressivos e resistentes. A esse respeito, Faraco (2008, p. 49) adverte:

Apesar desse poder centrípeto que a linguagem urbana comum exerce sobre as variedades do português popular, não podemos deixar de notar que talvez esteja se consolidando, entre as gerações mais novas da população urbana da chamada periferia das grandes cidades, uma certa resistência a esse poder centrípeto. 0 rap (que tem ocupado espaço nos meios de comunicação sociall e as manifestações literárias como a de Ferréz, entre outros, podem estar sinalizando uma crescente direção anti-homogeneização. Só o estudo empírico sistemático e o futuro poderão esclarecer e confirmar (ou não) essa nossa impressão.

Nossas observações têm demonstrado esse fenômeno agravado pela sua falta de percepção por parte dos professores. Nas anotações de campo, reiteradas observações do distanciamento dos alunos em relação ao discurso da escola.

8. Sobre o conceito de redes sociais em Bortoni-Ricardo (2011). 


\section{$08 / 10 / 2012$}

Os alunos são difíceis de serem motivados, conversam bastante durante a aula e qualquer fato thes tira a atenção. Os mais participativos, apesar de todos conversarem sobre outros assuntos durante a aula, foram o Vagner, o Sérgio e, um pouco menos, a Melissa; o restante dos alunos pouco prestavam atenção na aula. Fazer com que as aulas sejam motivadoras e envolventes na percepção dos alunos é um grande desafio para as professoras desta escola.

Por outro lado, observa-se também o distanciamento das professoras em relação à inserção da reflexão sociolinguística nas propostas didáticas. Como exemplo, numa das atividades com o gênero notícia, a professora $\mathrm{R}$ se preocupou em levar os alunos a perceberem as diferentes abordagens dos jornais relativamente a seu público alvo, mas sequer tocou na questão da variedade linguística. Isso motivou o seguinte comentário da bolsista numa de suas anotações de campo:

\section{$19 / 11 / 2012$}

Considero que a professora $\mathrm{R}$, ao fazer menção ao público alvo de cada jornal, deveria ter explicado o porquê disso, talvez por meio de expressões utilizadas nos jornais ou mostrando os tipos de notícias, entre outros meios. Ela não possibilitou nenhuma pista que faria os alunos enxergarem qual era o público, e tampouco a linguagem utilizada em cada jornal.

As poucas reflexões, nessa área, se mostraram incidentais, como a que foi feita pela própria bolsista que assessorava uma aluna:

\section{6/11/2012}

Além disso, algumas vezes, a aluna $L$ não fazia marcação de concordância do artigo com o substantivo no plural, como, por exemplo, em "os motorista". Expliquei a ela que, quando estamos conversando em casa ou com nossos amigos, não há problema em usarmos esta construção, mas quando estamos escrevendo, somos mais monitorados, ainda mais por estarmos em um ambiente escolar, então devemos ter cautela. Além da concordância nominal, a aluna, algumas vezes, não fazia a concordância verbal.

Noutro momento, a bolsista comenta:

\section{$22 / 10 / 2012$}

Considero que essa atividade de reescrita é boa para que os alunos possam treinar melhor sua produção de texto; no entanto, percebi que a aula dessa professora precisa ser mais direcionada, ou seja, não dá para perceber qual a competência que ela está buscando desenvolver nos alunos e, em consequência, o objetivo de sua aula.

Tudo indica, portanto, que um trabalho inteiro está por se fazer, nesse contexto escolar, em relação à pedagogia da variação linguística, desde a formação continuada das professoras à efetiva incorporação, em suas aulas, de uma reflexão adequada 
sobre as diferenças nos usos da língua e sua legítima existência numa sociedade multidialetal.

\section{Intervenções da pesquisa-ação}

Tendo em vista as práticas observadas e conforme a metodologia proposta no projeto, iniciamos um sistemático trabalho de intervenção pedagógica, feito indiretamente, por meio das próprias professoras regentes de sala. Embora três dentre elas tivessem se mostrado sensíveis e motivadas para o trabalho conjunto, à luz dos pressupostos teóricos acima apresentados, especialmente com uma conseguimos um trabalho mais efetivo nessa primeira fase aqui relatada. Nossos contatos acontecem semanalmente, na Faculdade de Educação, quando se reúne a equipe constituída das duas pesquisadoras, a professora que se tornou alvo permanente da intervenção e as alunas bolsistas de iniciação científica. Nesses encontros, não apenas são discutidas as questões constantes das anotações de campo, mas implementa-se também a busca de planejamento para fazer face às deficiências percebidas, do ponto de vista das experiências linguísticas dos alunos e das propostas pedagógicas requeridas para o professor. A leitura e o estudo de textos de linguística enunciativa, gêneros textuais e sociolinguística educacional fazem parte, sistematicamente, desses momentos. Desse modo, busca-se, nesse material, o suporte para promover o avanço nas intervenções pedagógicas.

Todas as questões acima apresentadas nas anotações de campo que revelavam despreparo teórico tornaram-se alvo de replanejamento: ainda que apenas com uma professora até o momento, tanto do ponto de vista dos gêneros textuais, quanto da sua concretização em ações enunciativas, as atividades didáticas adquiriram nova cor. Propostas de reflexão sobre diversidade linguística e dialetal levaram os alunos a tomar consciência da variação linguística, de modo que eles já se iniciam num processo de busca de adequação ao falar e escrever, tendo em vista o desenvolvimento de competência de uso das variedades cultas da língua, já quase transformado em desejo. Por exemplo, assistindo a um programa de Rolando Boldrin, espontaneamente se expressaram sobre a diferença dialetal do apresentador ao se dirigir ao público e ao contar seus "causos".

Da mesma forma, o trabalho com os gêneros textuais se tornou sistemático: além da "contação de causos", a entrevista já se tornou alvo da construção de uma sequência didática para levá-los a entrevistar um moçambicano sobre sua cultura, seu dialeto. Ao mesmo tempo, portanto, em que percebem diretamente as diferenças dialetais, iniciam-se nesse gênero discursivo muito atual.

Conforme depoimento espontâneo da professora no grupo de reflexão, tudo isso tem levado os alunos a querer escrever. Visto à luz da pedagogia da variação linguística e ensino de gêneros, esse avanço representa, possivelmente, um dos 
caminhos a serem efetivamente implementados na escola para se vencer o enorme desafio dos tempos atuais relativo à formação de produtores de texto e leitores competentes e maduros na sociedade brasileira.

\section{Considerações finais}

Embora tenha havido a divulgação das orientações e parâmetros curriculares (PCN, PCN+ e outros) das políticas de formação continuada adotadas nos últimos anos pelas secretarias de estado de educação e da grande oferta de cursos de especialização na área de ensino de língua portuguesa, temos verificado que ainda há problemas, e muitos, a vencer. Constatamos que, na verdade, nem todos os professores dessa disciplina, na escola alvo de nossa pesquisa, se apossaram da importância do estudo de gênero textual, nem o tomam como objeto de ensino para o desenvolvimento da competência linguística e discursiva de seus alunos. Por outro lado, também não fazem uso de uma pedagogia da variação como fundamento de suas práticas escolares.

Sabemos que essa situação particular é emblemática do que tem ocorrido, de maneira geral, nas escolas brasileiras. Reiteramos as já conhecidas conclusões que apontam para a necessidade de um trabalho efetivo de formação continuada dos professores.

Acreditamos, no entanto, que a compreensão da teoria dos gêneros associada à incorporação das propostas da sociolinguística educacional constituam uma ferramenta indispensável para o sucesso do trabalho de educação linguística na escola.

\section{Referências}

BAKHTIN, Mikhail. Estética da criação verbal. São Paulo: Martins Fontes, 1953/2000. BORTONI-RICARDO, Stella Maris. Educação em língua materna: a sociolinguística na escola. São Paulo: Parábola, 2004.

Stella Maris. Nós cheguemu na escola, e agora?: sociolinguística \& educação. São Paulo: Parábola, 2005.

. Do campo para cidade: estudo sociolinguístico de migração e redes sociais. São Paulo: Parábola, 2011.

BRASIL. Parâmetros curriculares nacionais de língua portuguesa para o $3^{\circ}$ e $4^{\circ}$ ciclos do Ensino Fundamental. Brasília: Ministério da Educação, 1999.

BRONCKART, J. P. Atividades de Linguagem, textos e discursos: por um interacionismo sócio-discursivo. São Paulo: EDUC, 1999.

BRONCKART, J.P. Gêneros textuais, tipos de discursos e operações psicolingüísticas. 
Revista de Estudos da Linguagem. 2003, Belo Horizonte: vol. 11- n.1, p.49-69.

CASTILHO, Ataliba Teixeira de. Variação dialetal e ensino institucionalizado da língua portuguesa. In: BAGNO, M. (Org.). Linguística da norma. São Paulo: Parábola, 2002. p.27-36.

DOLZ, J.; PASQUIER, G.; BRONCKART, J. P. A aquisição do discurso: emergência de uma competência ou aprendizagem de capacidades linguageiras diversas? Estudos de Linguística Aplicada, n. 89, p. 25-35, 1993.

DOLZ, J.; NOVERRAZ, M.; SCHNEUWLY, B. Sequências didáticas para o oral e a escrita: apresentação de um procedimento. In: SCHNEUWLY, B.; DOLZ, J. \& colaboradores. Gêneros orais e escritos na escola. Campinas: Mercado de Letras, 2004, p. 95-128.

DOLZ, J.; SCHNEWLY, Bernard. Gêneros e progressão em expressão oral e escrita - elementos para reflexões sobre uma experiência suíça (francófona), In: ᄀDOLZ, J.; SCHNEWLY, Bernard e colaboradores. Gêneros orais e escritos na escola. Campinas: Mercado de Letras, 2004, p. 41-70.

FARACO, Carlos Alberto. Norma culta brasileira: desatando alguns nós. São Paulo: Parábola, 2008.

LABOV, Wiliam. Can reading failure be reversed?: a linguistic approach to the question. In : V.Gadsen; D. Wagner (Ed). Literacy Among African-American Youth. Cresskill, NJ: Hampton Press, 1995.

PRETI, Dino. A propósito do conceito de discurso urbano oral culto: a língua e as transformações sociais. In: Humanitas/FFLCH/USP, 1997. p. 17-27. (Org.). O discurso oral culto. São Paulo: ROJO, Roxane (org.). Letramentos múltiplos, escola e inclusão social. São Paulo: Parábola, 2009.

SWALES, J. M. Genre analysis: English in academic and research settings. New York: Cambridge University Press, 1990.

SOARES, Magda. Linguagem e escola: uma perspectiva social. 3. ed. São Paulo: Ática, 1986.

WHEELER. Rebecca S.; SWORDS, Rachel. Codeswitching: tolls of language and cultures transform the dialectally diverse classroom. Laguage Arts, [sine loco], v. 81, n. 6, july 2004, p. 471-480.

. Teaching English in the word. English journal, Stony Brook University, v.94, p.108-112, may 2005.

. Becoming adept at code-switching. Educational leaderschip, Alexandria (VA), 65, n. 7, p. 54-58, april 2008.

WOLFRAM, Walt. Repercussions from the Oakland Ebonics controversy. The critical role of dialect awareness programs. In: Adger, Carolyn, Temple; Donna Cristian; Orlando Taylor (ed). Making the connection: language and academic achievement among African American students. Mchenry, IL: Delta Systems,1999. p.61-80. VYGOTSKY, L. S. Pensamento e linguagem. São Paulo: Martins Fontes, ([1936]1996). 
Recebido em março de 2013

Aprovado em outubro de 2013

Lúcia Cyranka é doutora em Letras pela Universidade Federal Fluminense e professora da área de linguagem, graduação e pós-graduação, na Faculdade de Educação da Universidade Federal de Juiz de Fora. E-mail: lucia.cyrankaQuuol.com.br

Terezinha Barroso é doutora em Letras pela Pontifícia Universidade Católica do Rio de Janeiro e professora convidada no curso de especialização Ensino de Língua Portuguesa da Faculdade de Letras da Universidade Federal de Juiz de Fora e no curso de Mestrado Profissional em Gestão e Avaliação da Educação Pública da Faculdade de Educação da Universidade Federal de Juiz de Fora.. E-mail: terezinha. barrosolufjf.edu.br 